\title{
AVALIAÇÃO DA DISPONIBILIDADE DE TECIDO ÓSSEO PARA ENXERTO PROVENIENTE DA REGIÃO DE MENTO. ESTUDO COMPARATIVO ENTRE TOMOGRAFIA COMPUTADORIZADA DE FEIXO CÔNICO, TELERRADIOGRAFIA LATERAL E RADIOGRAFIA PANORÂMICA
}

\author{
Stéphanie M. M. Araújo (PQ), Gustavo M. Santaella (PG), Thiago de O. Gamba (PG), Luciana Asprino.
}

\section{Resumo}

São várias as utilidades de enxertos ósseos autógenos na Cirurgia Buco-Maxilo-Facial, desde correção de deformidades faciais, até para possibilitar instalação de implantes nos rebordos alveolares atróficos. Diversos exames de imagens são utilizados para avaliar a disponibilidade de enxerto ósseo disponível em áreas intrabucais. O objetivo deste trabalho foi comparar mensurações nas avaliações de enxerto ósseo disponível em região de mento por meio de radiografias panorâmicas, telerradiografias laterais e tomografias computadorizadas de feixe cônico (TCFC). As medidas não apresentaram diferenças entre panorâmica e TCFC, quando estas ampliadas em $30 \%$. A espessura óssea a $3 \mathrm{~mm}$ do ápice dental e a $5 \mathrm{~mm}$ da base da mandíbula não apresentaram diferenças entre telerradiografias laterais e TCFC para região de incisivo central esquerdo ( $3 \mathrm{~mm}$ e $5 \mathrm{~mm})$, incisivo lateral esquerdo $(3 \mathrm{~mm})$ e canino esquerdo $(5 \mathrm{~mm})$.

Palavras Chave: radiografia panorâmica, tomografia computadorizada de feixe cônico, enxerto de osso alveolar.

\section{Introdução}

Os enxertos ósseos são de muita importância na prática cirúrgica-odontológica, particularmente nas reconstruções dos rebordos alveolares atróficos para instalação de implantes dentários.

Ao se avaliar a área do sítio doador, além do exame físico deve-se considerar os exames por imagem, que possibilitam a avaliação prévia da quantidade óssea disponível, bem como aferir a proximidade com estruturas que possam limitar a região a ser removida.

\section{Resultados e Discussão}

Foram realizadas, após a aprovação do Comitê de Ética em Pesquisa em Seres Humanos da Faculdade de Odontologia de Piracicaba UNICAMP sob 0 protocolo no081/2014, mensurações em radiografias panorâmicas, telerradiografias laterais e tomografias computadorizadas de feixe cônico (TCFC) de 106 pacientes, da região anterior de mandíbula.

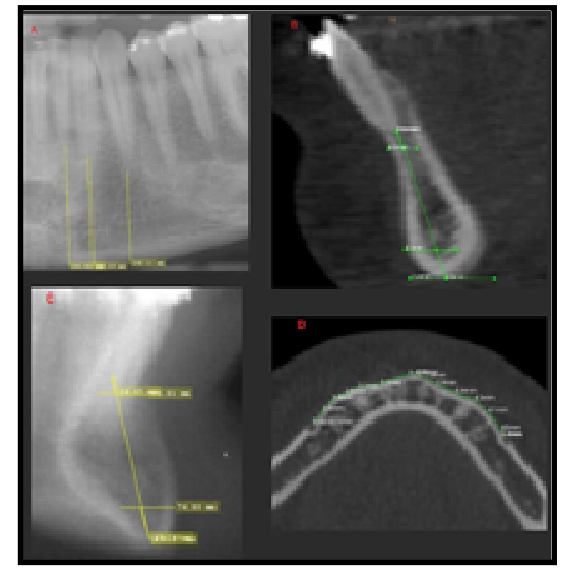

A análise estatística das medidas foi feita por meio do teste de análise de variância para um critério, com teste post-hoc de Tukey.

\begin{tabular}{|c|c|c|c|c|c|c|c|c|}
\hline \multirow{2}{*}{ Exame } & \multicolumn{2}{|c|}{ Forame - forame } & \multicolumn{2}{|c|}{ Inc. central - base } & \multicolumn{2}{|c|}{ Inc. lateral - base } & \multicolumn{2}{|c|}{ Canino - base } \\
\hline & Média & DP & Média & DP & Média & DP & Média & DP \\
\hline \begin{tabular}{l|l} 
Panorâmica & 6 \\
\end{tabular} & $66,3 \mathrm{a}$ & 10,2 & $28,1 \mathrm{c}$ & 3,6 & $26,8 \mathrm{e}$ & 3,6 & $22,5 \mathrm{~g}$ & 3,2 \\
\hline TCFC & $50,3 \mathrm{~b}$ & 2,9 & $21,0 \mathrm{~d}$ & 2,5 & $20,2 f$ & 2,4 & $17,1 \mathrm{~h}$ & 2,0 \\
\hline \begin{tabular}{l|l} 
TCFC $130 \%$ & 6
\end{tabular} & $65,4 \mathrm{a}$ & 3,8 & $27,3 \mathrm{c}$ & 3,3 & $26,3 \mathrm{e}$ & 3,2 & $22,2 \mathrm{~g}$ & 2,7 \\
\hline & \multicolumn{3}{|c|}{ Ápice - base } & \multicolumn{2}{|c|}{ Largura - 3mm do ápice } & \multicolumn{3}{|c|}{ Largura - $5 \mathrm{~mm}$ da base } \\
\hline & \multicolumn{2}{|l|}{ Média } & DP & Média & DP & \multicolumn{2}{|c|}{ Média } & DP \\
\hline Telerradiografia & \multicolumn{2}{|l|}{ fia 24,0 a } & 4,1 & $6,7 \mathrm{~d}$ & 2,4 & \multicolumn{2}{|c|}{$8,6 f$} & 1,3 \\
\hline Tomografia IC & \multicolumn{2}{|l|}{$20,8 \mathrm{~b}$} & 3,0 & $7,2 d$ & 2,3 & \multicolumn{2}{|c|}{$8,3 \mathrm{fg}$} & 1,3 \\
\hline Tomografia IL & \multicolumn{2}{|l|}{$20,4 b$} & 2,8 & $7,2 \mathrm{~d}$ & 2,1 & \multicolumn{2}{|c|}{$8,0 \mathrm{~g}$} & 1,3 \\
\hline Tomografia C & \multicolumn{2}{|l|}{$17,9 \mathrm{c}$} & 2,6 & $8,8 \mathrm{e}$ & 2,2 & \multicolumn{2}{|c|}{$8,5 \mathrm{fg}$} & 1,6 \\
\hline
\end{tabular}

Medidas em $\mathrm{mm}$. Letras diferentes em uma mesma coluna indicam diferenças estatisticamente significantes.

\section{Conclusões}

Após a avaliação dos dados, concluiu- se que:

- As medidas entre panorâmica e TCFC apresentaram diferenças, porém não houve diferenças quando as medidas da TCFC foram ampliadas em 30\% (ampliação média da panorâmica).

- As medidas de altura óssea entre telerradiografia lateral e TCFC apresentaram diferenças, mas não as de largura óssea a $3 \mathrm{~mm}$ do ápice em incisivo central e lateral esquerdos, e a $5 \mathrm{~mm}$ da base da mandíbula na região de incisivo central e canino esquerdo.

\section{Agradecimentos}

Ao programa $\mathrm{CNPq} / \mathrm{PIBIC}$ pelo financiamento do projeto de pesquisa, e à FOP-UNICAMP pelos dados fornecidos.

FLORIAN, F. et al. Enxertos intrabucais para reconstrução de áreas edêntulas: relato de casos clínicos. Revista de Odontologia da UNESP, v. 37, n. Especial 2, p. 2577,9 abr. 2008

SILVA NETO, J. C.; PONTUAL, A. DOS A.; CARIBÉ, P. M. V. Avaliação linear da espessura óssea da região mentual para enxertos ósseos intraorais. Rev. cir. traumatol. buco-maxilo-fac, v. 10, n. 2, p. 77-82, 2010. 